Mill, Moore, and Intrinsic Value

Author(s): Guy Fletcher

Source: Social Theory and Practice, Vol. 34, No. 4 (October 2008), pp. 517-532

Published by: Florida State University Department of Philosophy

Stable URL: http://www.jstor.org/stable/23562094

Accessed: 22-12-2015 14:48 UTC

\title{
REFERENCES
}

Linked references are available on JSTOR for this article:

http://www.jstor.org/stable/23562094?seq=1\&cid=pdf-reference\#references_tab_contents

You may need to $\log$ in to JSTOR to access the linked references.

Your use of the JSTOR archive indicates your acceptance of the Terms \& Conditions of Use, available at http://www.jstor.org/page/ info/about/policies/terms.jsp

JSTOR is a not-for-profit service that helps scholars, researchers, and students discover, use, and build upon a wide range of content in a trusted digital archive. We use information technology and tools to increase productivity and facilitate new forms of scholarship. For more information about JSTOR, please contact support@jstor.org.

Florida State University Department of Philosophy is collaborating with JSTOR to digitize, preserve and extend access to Social Theory and Practice. 


\section{Mill, Moore, and Intrinsic Value}

In this paper, I examine how philosophers before and after G.E. Moore understood intrinsic value. The main idea I wish to bring out and defend is that Moore was insufficiently attentive to how distinctive his conception of intrinsic value was, as compared with those of the writers he discussed, and that such inattentiveness skewed his understanding of the positions of others that he discussed and dismissed. My way into this issue is by examining the charge of inconsistency that Moore levels at the qualitative hedonism outlined by J.S. Mill in Utilitarianism. Along the way I suggest that there are a number of ways in which Moore was unfair in rejecting qualitative hedonism as inconsistent. I close by relating the issues that arise in discussion of Moore to contemporary debates on value and reasons.

\section{Mill's Qualitative Hedonism}

One of the most notorious passages of Mill's Utilitarianism comes when he outlines his qualitative hedonism as follows:

It is quite compatible with the principle of utility to recognise the fact that some kinds of pleasure are more desirable and more valuable than others. It would be absurd that, while in estimating all other things quality is considered as well as quantity, the estimation of pleasures should be supposed to depend on quantity alone. ${ }^{1}$

Mill's qualitative hedonism is often held to be inconsistent. ${ }^{2}$ By this it is, commonly, meant that although (like all hedonistic theories) it purports

\footnotetext{
${ }^{1}$ J.S. Mill, Utilitarianism [1861], ed. George Sher (Indianapolis: Hackett, 2000), p. 8 (my italics)

${ }^{2}$ The objection that qualitative hedonism is inconsistent is to be found in many places, including F.H. Bradley, Ethical Studies, 2nd ed. (Oxford: Oxford University Press, 1988), pp. 116-23; T.H. Green, Prolegomena to Ethics [1883], ed. David O. Brink (Oxford: Oxford University Press, 2003), pp. 183-90; Hastings Rashdall, The Theory of Good and Evil: A Treatise on Moral Philosophy, Part One [1907] (Montana: Kessinger Publishing, 2005), p. 27; and David Ross, The Right and the Good [1930], ed. Philip Stratton-Lake (Oxford: Oxford University Press, 2002), p. 145. However, I think it misleading to talk of "the objection" in the singular as I think that there are, in fact, a cluster of distinct 
to be monistic, it is in fact pluralistic (or, in short, that the qualitative part is inconsistent with the hedonism part). And in Principia Ethica, G.E. Moore objects to Mill along precisely these lines:

I have pointed out that, if you say, as Mill does, that quality of pleasure is to be taken into account, then you are no longer holding that pleasure alone is good as an end, since you imply that something else, something which is not present in all pleasures, is also good as an end. ${ }^{3}$

I think that Moore (like some before and after him) is unfair in his treatment of Mill in a number of ways. I think that even if it is unmotivated and false, qualitative hedonism is consistent. This is not a new claim. I hope, however, to provide an interesting and illuminating explanation of the unfairness, by showing that Moore's objection to Mill's hedonism unduly presupposed (among other things) Moore's substantive view of intrinsic value.

\section{Moore's View of Intrinsic Value}

Moore's view of intrinsic value (implicit in Principia, and articulated and defended later in "The Conception of Intrinsic Value") consists of one claim supplemented by two further claims. ${ }^{5}$ Moore outlines the first claim as follows:

To say that a kind of value is "intrinsic" means merely that the question whether a thing possesses it, and in what degree it possesses it, depends solely on the intrinsic nature of the thing in question. ${ }^{6}$

Moore then expands further on what he means by saying that intrinsic value depends "solely on the intrinsic nature of the thing in question," and provides a pair of claims as follows:

inconsistency objections in the considerable literature on the topic. Bradley, for instance, seems to offer an objection that is different from that made by Green and Moore. Bradley's objection is based on the inconsistency of qualitative hedonism with "the greatest amount" theory.

${ }^{3}$ G.E. Moore, Principia Ethica [1903], revised ed., ed. Thomas Baldwin (Cambridge: Cambridge University Press, 1993), p. 132 (italics in original).

${ }^{4}$ This is not to claim that Moore's discussion and objection to Mill is unique. Rather, I frame the discussion in terms of Mill and Moore on the grounds that either Moore's objection is unique or, if it is not, that he is a prominent representative of a source of objection to Mill's theory.

${ }^{5}$ G.E. Moore, "The Conception of Intrinsic Value," in G.E. Moore, Philosophical Studies (London: K. Paul, Trench, Trubner \& Co., 1922). Page numbers in the notes refer to its reprinting in Baldwin's 1993 edition of Principia Ethica, pp. 280-98.

${ }^{6}$ Moore, "The Conception of Intrinsic Value," p. 286 (italics in original). 
[I]t is impossible for what is strictly one and the same thing to possess that kind of value [i.e., intrinsic value] at one time, or in one set of circumstances, and not to possess it at another; and equally impossible for it to possess it in one degree at one time, or in one set of circumstances, and to possess it in a different degree at another, or in a different set. ${ }^{7}$

[I]f a given thing possesses any kind of intrinsic value in a certain degree, then not only must that same thing possess it, under all circumstances, in the same degree, but also anything exactly like it, must, under all circumstances, possess it in exactly the same degree. ${ }^{8}$

So, on Moore's view, if Y possesses intrinsic value today, then all of the following must be true:

(a) Y's intrinsic value depends solely upon its intrinsic properties.

(b) Y must also possess intrinsic value (and to the same degree) at any other time or place at which it exists.

(c) Anything with the same intrinsic properties as $\mathrm{Y}$ must possess intrinsic value (and to the same degree) as $\mathrm{Y}$.

\section{How Mill Could Have Been Consistent (Even on Moore's Terms)}

I think that Moore is multiply uncharitable in his reading of Mill and that Mill's qualitative hedonism can be rendered consistent, even on Moore's own terms, in a number of different ways. I shall not cover them all here but will pause briefly to examine three that I consider to be important.

One way of making qualitative hedonism work within Moore's theory would simply be to regard the quality of a pleasure as an intrinsic property of it. And Mill does perhaps think of quality as an intrinsic property, as suggested by his writing:

And there needs be the less hesitation to accept this judgement respecting the quality of pleasures, since there is no other tribunal to be referred to even on the question of quantity. What means are there of determining which is the acutest of two pains, or the intensest of two pleasurable sensations, except the general suffrage of those who are familiar with both? Neither pains nor pleasures are homogeneous, and pain is always heterogeneous with pleasure. ${ }^{10}$

\footnotetext{
${ }^{7}$ Ibid. (italics in original).

${ }^{8}$ Ibid., p. 287 (italics in original).

${ }^{9}$ As will be apparent, Moore's conception of intrinsic value will seemingly get into difficulties if, as seems plausible, some intrinsic properties of intrinsically valuable things are contingent. This, coupled with the claim that changes in intrinsic properties could result in changes in intrinsic value, would drive a wedge between Moore's (a) and (b). Perhaps Moore was already assuming that the bearers of intrinsic value are states of affairs, given that these do have all their intrinsic properties with necessity. For more on this issue see, for instance, Jonathan Dancy, Ethics without Principles (Oxford: Oxford University Press, 2004), p. 168.

${ }^{10}$ Mill, Utilitarianism, p. 11 (my italics).
} 
If quality were an intrinsic property of a pleasure, then it seems that qualitative hedonism need not (a) violate Moore's intrinsicality or necessity theses, nor (b) slide into pluralism. One might try to object to such a theory by saying that only the intrinsic properties relating to quantity (that is, intensity and duration) can be relevant to determining the value of a pleasure. But it is not clear what (particularly in Moore's account of intrinsic value) would justify such a restriction.

Moore does pause to consider this version of Mill's theory:

For take even the most favourable supposition of his meaning; let us suppose that by a pleasure he does not mean, as his words imply, that which produces pleasure and the pleasure produced. Let us suppose him to mean that there are various kinds of pleasure, in the sense in which there are various kinds of colour-blue, red, green, etc. ${ }^{11}$

Moore, however, quickly dismisses the position as inconsistent on the grounds that it commits "the fallacy of confusing ends and means." $\mathrm{He}$ elaborates upon the charge by writing that "if colour is our only possible end, as Mill says pleasure is, then there can be no possible reason for preferring one colour to another, red, for instance, to blue, except that the one is more of a colour than the other."12

It is hard to tell how good an argument this is against this version of Mill's theory (one in which pleasures differ in their intrinsic nature). Apparently Moore just does not take sufficiently seriously the idea of pleasures differing in quality - as suggested by his thinking that the particular kinds of pleasure would be means to some homogeneous "pleasure." It is tempting to see Moore as retaining Bentham's conception of pleasure-in which pleasures are homogeneous feelings varying (intrinsically) only in their intensity and duration-despite Mill's position being explicitly in opposition to this. ${ }^{13}$

Of course, it may be true that pleasures do not differ in quality, so there are not the different kinds of pleasure that the position being considered here suggests (although it is interesting to note that it later became common to reject hedonism on the ground that it postulated a common quality to all instances of pleasure that, in fact, did not exist). ${ }^{14}$

\footnotetext{
${ }^{11}$ Moore, Principia, p. 131. The passage continues: "Even in this case, if we are to say that our end is colour alone, then, although it is impossible we should have colour without having some particular colour, yet the particular colour we must have, is only a means to our having colour, if colour is really our end."

${ }^{12}$ Ibid.

${ }^{13}$ For example, Bentham writes: "The great difficulty lies in the nature of the words; which are not, like pain and pleasure, names of homogeneous real entities, but names of various fictitious entities, for which no common genus can be found.” Jeremy Bentham, An Introduction to the Principles of Morals and Legislation [1789], chap. VI, n. 39.

${ }^{14}$ Rashdall, The Theory of Good and Evil, Part II, p. 32, calls qualitative hedonism inconsistent, and his objection is that pleasures are homogeneous (à la Bentham). For the
} 
But, pace (for instance) Hastings Rashdall, this does not make qualitative hedonism inconsistent, as it was (and still is) often held to be. Looking at Moore's charge, it is not clear why such a quality-as-intrinsic position would have to say that the various kinds of pleasure were each a means to the real end ("pleasure"). Nor is it clear why the holder of such a position would have to say, as Moore contends, that the higher quality pleasures were "more of a pleasure" than the lower quality ones. It seems that they could just say that they are better.

I think that by making the quality of a pleasure an intrinsic property of it, a qualitative form of hedonism can be rendered consistent on Moore's terms (that is, with his two theses of intrinsic value). I also think it is unclear what Moore's argument against such a position comes to (as it is presented in the passage above).

There is a second way in which Moore could have made Mill's qualitative hedonism consistent. Moore could, for instance, have attributed to Mill his (Moore's) own ontology of value bearers, ${ }^{15}$ that is, by holding that states of affairs be the bearers of intrinsic value. ${ }^{16}$ This is because even if quality were an extrinsic property of the pleasure, it would be an intrinsic property of the relevant state of affairs. ${ }^{17}$ So, as long as it is a state of affairs that is the bearer of value, quality can be an extrinsic property of the pleasure and qualitative hedonism can still be consistent with Moore's view of value. ${ }^{18}$

objection that hedonism postulates a common quality to all instances of pleasure that in fact does not exist, see, for example, James Griffin, Well-Being: Its Meaning, Measure, and Moral Importance (Oxford: Clarendon Press, 1986), p. 8, and Derek Parfit, Reasons and Persons (Oxford: Clarendon Press, 1984), p. 493.

${ }^{15}$ As I read it, this ontology of value bearers is not explicit in Principia, but Moore makes clear a commitment to it in his Philosophical Studies, writing (p. 327): "One thing, I think, is clear about intrinsic value-goodness in Aristotle's sense-namely that it is only actual occurrences, actual states of things over a certain period of time-not such things as men, or characters, or material things, that can have any intrinsic value at all."

${ }^{16}$ On this, see Wlodek Rabinowicz and Toni Rønnow-Rasmussen, "A Distinction in Value: Intrinsic and For Its Own Sake," Proceedings of the Aristotelian Society 100 (2000): 33-51.

${ }^{17}$ For an example of this proposal worked out in full, see Fred Feldman, "Mill, Moore, and the Consistency of Qualified Hedonism," in Peter French, Theodore Uehling, Jr., and Howard Wettstein (eds.), Midwest Studies in Philosophy, vol. 20 (Notre Dame: University of Notre Dame Press, 1996), pp. 318-31.

${ }^{18}$ Shelly Kagan perhaps dissents from this in "Rethinking Intrinsic Value." He writes (pp. 112-13) that those in the Moorean tradition "would want to say something like the following: if facts are indeed the only bearers of intrinsic value, then we must also place a restriction on what sorts of ascribed properties are relevant to intrinsic value. Only intrinsic ascribed properties can be relevant. That is, if a fact has intrinsic value, it can only be by virtue of ascribing intrinsic properties to its object." Shelly Kagan, "Rethinking Intrinsic Value," The Journal of Ethics 2 (1998): 277-97. Page numbers in the notes refer to its reprinting in Toni Rønnow-Rasmussen and Michael J. Zimmerman 
A third way for Moore to make qualitative hedonism work on his own terms is with his conception of an organic unity. Moore's idea of an organic unity allows for the intrinsic value of a complex whole to exceed the invariant intrinsic value of its parts. Most often this is discussed in the context of retributive theories of punishment, as a way of making sense of how responding to something bad (crime) with another bad (punishment) can be better than leaving the crime unpunished. ${ }^{19}$ However, the same idea can be applied to Mill's qualitative hedonism. Moore could think that when a pleasure is combined with the operation of a certain faculty - a higher one, say - the whole produced is more valuable than the combination of a pleasure of equal intensity and duration with another (lower) faculty. This can be done whilst retaining the idea that the operation of the faculties is, itself, intrinsically neutral. To put the point schematically, and highly artificially, the respective organic unities would be as follows:

Pleasure $(+5) \&$ Use of higher faculty $(0)=$ "Higher pleasure" Organic Unity $(+10)$

Pleasure $(+5) \&$ Use of lower faculty $(0)=$ "Lower pleasure" Organic Unity $(+5)$

This is not to suggest that Mill had this idea in mind. It is only to suggest yet another way in which Moore could have made Mill's theory consistent on Moore's own terms. What is more important for my broader aim here is that Moore's presentation and discussion of the quality-as-intrinsic position suggests that he takes Mill's talk of "pleasure" to mean "that which produces pleasure and the pleasure produced." So the default picture of Mill's theory that Moore operates with is one in which the quality of a pleasure is an extrinsic property of it (like a causal property). And this is relevant to seeing how the inconsistency charge he makes against Mill may have partly stemmed from his own substantive view of intrinsic value.

\section{Moore's Reading of Mill}

It seems reasonable to think that Mill would have gone awry if he had held the combination of Moore's substantive account of intrinsic value

(eds.), Recent Work on Intrinsic Value (Dordrecht: Springer, 2005), pp. 97-114.

${ }^{19}$ See for instance, Michael Clark, "Retribution and Organic Unities," Journal of Moral Philosophy 3 (2006): 351-58; Jonathan Dancy, "Moore's Account of Vindictive Punishment: A Test Case for Theories of Organic Unities," in Susana Nuccetelli and Gary Seay (eds.), Themes from G.E. Moore: New Essays in Epistemology and Ethics (Oxford: Oxford University Press, 2007), pp. 325-42; and Thomas Hurka, "Moore in the Middle," Ethics 113 (2003): 599-628. 
and the claim that an extrinsic property (the faculty it derives from) can affect the value of a pleasure. And it is easy to see how Moore could have read the second claim into Mill, such as when Mill writes:

When, therefore, those feelings and judgement [those of competent judges] declare the pleasures derived from the higher faculties to be preferable in kind, apart from the question of intensity, to those of which the animal nature, disjoined from the higher faculties, is susceptible, they are entitled on this subject to the same regard [to have their view admitted as final]. ${ }^{20}$

To help to see how Moore's view of intrinsic value may have led to his inconsistency objection to Mill, an example might be useful:

Situation A: X gets a pleasure of a certain intensity and duration from reading Plato.

Situation B: Y gets a pleasure of the same intensity and duration as X's from swinging on an office chair.

Let us imagine that although the pleasures in the two scenarios are of equal intensity and duration, situation A is better (a " +7 ," so to speak, rather than a " +5 ") and let us leave open (for the moment) why it is so.

Given Moore's view of intrinsic value, the value of a pleasure is fixed and cannot be allowed to be affected by an extrinsic feature such as its provenance. To do so would violate the intrinsicality thesis as it would not be the intrinsic nature of the things alone that determined their value. It would also violate the necessity thesis because the very same thing might not then have the same intrinsic value in every context in which it appears. What this means is that if a situation containing a pleasure of a particular intensity and duration is more valuable than another situation containing a pleasure of equal intensity and duration, ${ }^{21}$ this cannot be accounted for by an extrinsic feature of the pleasure, such as its origin (unless we give up hedonism).

For Moore, the only thing that could explain the divergence in value between the two situations is that something else of intrinsic value (the deployment of one's higher faculties rather than one's lower faculties, perhaps) is present in the one situation. There is no divergence in the value of the pleasure between the two situations. Rather, there is the supplementing of the valuable pleasure with another valuable thing (the respective value of the faculty from which it originates). So we get a valuable end that is on occasion more valuable because of the means by which it is achieved. And so, from this, Mill's qualitative hedonism

\footnotetext{
${ }^{20}$ Mill, Utilitarianism, p. 11 (my italics).

${ }^{21}$ Remember that here we are treating quality as an extrinsic property, whether or not this is what Mill actually held.
} 
slides into pluralism.

And I think we can find this line of thought in Moore's attempt to redescribe (and thereby correct) what Mill might have held to be an instance of a pleasure being higher (and thereby) more valuable than another (despite equal intensity and duration). Moore writes:

Mill's judgement of preference, so far from establishing the principle that pleasure alone is good, is obviously inconsistent with it ... If one pleasure can differ from another in quality, that means, that $a$ pleasure is something complex, something composed, in fact, of pleasure in addition to that which produces pleasure. For instance, Mill speaks of "sensual indulgences" as "lower pleasures." But what is a sensual indulgence? It is surely a certain excitement of some sense together with the pleasure caused by such excitement. Mill, therefore, in admitting that a sensual indulgence can be directly judged to be lower than another pleasure, in which the degree of pleasure involved may be the same, is admitting that other things may be good, or bad, quite independently of the pleasure which accompanies them. $A$ pleasure is, in fact, merely a misleading term which conceals the fact that what we are dealing with is not pleasure but something else, which may indeed necessarily produce pleasure, but is nevertheless quite distinct from it. ${ }^{22}$

As mentioned above, Moore's view of intrinsic value prohibits an extrinsic property from affecting the intrinsic value of an instance of pleasure. And in this passage we can see how Moore's commitment to his substantive view of intrinsic value, and its inability to countenance extrinsic features affecting intrinsic value, leads him to accuse Mill of attributing value to something else (the excitement of some sense).

The issue, then, in assessing this part of Moore's inconsistency charge, is whether Mill held the same conception of intrinsic value as Moore. And to this question I now turn.

\section{Was Mill a Moorean?}

The short answer is that it is hard to tell. A feature of Mill's Utilitarianism is how rarely he uses the words "intrinsic" and "intrinsically" in discussing value. Most of the time Mill talks of things being "desirable as ends," "in themselves good," and "good as an end." More importantly, though, Mill's use of "intrinsic" and "intrinsically," and his talk of value generally, do not provide much that shows a commitment to a Moorean view of value. $^{23}$

Mill's uses of "intrinsically" come in his discussion of the value of virtue. Mill says:

\footnotetext{
${ }^{22}$ Moore, Principia, pp. 130-31 (italics in original).

${ }^{23}$ Mill's use of "intrinsic" and "intrinsically" in On Liberty and Principles of Political Economy also follows his usage in Utilitarianism-in suggesting the contrast between good ends and means, rather than a more substantive (Moorean) view of intrinsic value.
} 
That which is the result of habit affords no presumption of being intrinsically good; and there would be no reason for wishing that the purpose of virtue should become independent of pleasure and pain were it not that the influence of the pleasurable and painful associations which prompt to virtue is not sufficiently to be depended on for unerring constancy of action until it has acquired the support of habit ... In other words, this state of the will is a means to good, not intrinsically a good. ${ }^{24}$

It seems clear that the most that Mill's use of "intrinsically" gives us here is the contrast between something being good as a means and good as an end. And, Mill's using "intrinsic" and "intrinsically" in this way should make us wary of attributing Moore's view of intrinsic value to Mill. ${ }^{25}$ This is especially so if we bear in mind (for instance) Korsgaard's two distinctions in goodness (in short, the distinctions between intrinsic/ extrinsic value and final/instrumental value). ${ }^{26}$

As Korsgaard argues, the proper contrast to being good as a means to something good (instrumental value) is something that is good for its own sake (which she calls "final value"). And, on its own, this says nothing about whether things that are finally valuable are so in virtue of their intrinsic properties alone. Similarly, the proper contrast to the value a thing has that is grounded in its intrinsic features (intrinsic value) is the value it has that is grounded in its extrinsic features (extrinsic value). And in light of this it is possible that things may be good for their own sake on at least partly relational (extrinsic) grounds. ${ }^{27}$

Now, as is well known, Moore does not hold these two distinctions as separate. For Moore, if something is the opposite of a means to a good, then it must be intrinsically good. And if something is intrinsically good then it must adhere to the intrinsicality and necessity theses outlined above. So, if Moore had written what Mill wrote about virtue, then we should read the claim that good will is "not intrinsically a good" according to Moore's understanding (that is, as obeying the two theses). ${ }^{28}$ But it seems possible to hold that Mill's use of "intrinsically" refers only to what Korsgaard calls "final value," rather than intrinsic value in Moore's sense. And if we resist imputing Moore's equivalence between

\footnotetext{
${ }^{24}$ Mill, Utilitarianism, p. 41 (my italics).

${ }^{25}$ Given that Mill talks of quality as an intrinsic property, one might be tempted to ascribe Moore's view of intrinsic value to him. My claim is not that he did not hold such a view, only that there is insufficient evidence for it and that Moore could have considered whether Mill was not committed to such a strong view.

${ }^{26}$ Christine Korsgaard, "Two Distinctions in Goodness," Philosophical Review 92 (1983): 169-95.

${ }^{27}$ Ibid., passim.

${ }^{28}$ And, of course, Moore does, throughout Principia, talk of a distinction between something's being good as a means and its being intrinsically good, e.g. (p.73): "Their difference has, indeed, received expression in ordinary language by the contrast between the terms 'good as means' and 'good in itself', 'value as a means' and 'intrinsic value'."
} 
intrinsic and final value to Mill, then, pace Moore, there would have been nothing to stop Mill from having consistently held pleasures to be the only things that are good as ends and that their value can be affected by extrinsic properties such as their faculty of origin. ${ }^{29}$ These would be what Rabinowicz and Rønnow-Rasmussen call "nonintrinsic, final values. ${ }^{\prime 30}$ There would need to be an explanation of why such features can enhance the value of pleasure without themselves being valuable, but it is not clear that such an explanation is impossible. More importantly, though, this is a question of how well motivated the theory is, not whether it is consistent.

Moving to the present day, for the moment, we find another way of thinking about intrinsic value that could make sense of qualitative hedonism: Jonathan Dancy's holistic conception of intrinsic value. Dancy's conception involves a distinction between the ground of intrinsic value (the properties in virtue of which it is valuable) and its supervenience base (that upon which its value depends). ${ }^{31}$ Making these distinctions opens up the space for something's contributing to the explanation of the value a thing has without being part of what makes it valuable or what it is valuable in virtue of. Crucially, it can do this without itself being valuable. ${ }^{32}$ Two pairs of ways that Dancy identifies are by being enablers or disablers, and by being intensifiers or attenuators. ${ }^{33}$ Applied to qualitative hedonism, the idea of an intensifier or attenuator could allow us to say that the faculty of origin of a pleasure serves to enhance the intrinsic value of a pleasure. But it does not do this by being an extra value in addition to the value of the pleasure. ${ }^{34}$ Nor does its status as an intensifier require that it have any value at all.

In closing, let us move away from the specifics of how Dancy's view can make sense of qualitative hedonism and return to the general idea that there are less restrictive understandings of intrinsic value than Moore's and that Mill could have held one of them. In The Definition of Good, A.C. Ewing presents his own conception of intrinsic value, and

\footnotetext{
${ }^{29}$ This is not supposed to be a reading of what Mill did hold, only what he could (contra Moore) have held.

${ }^{30}$ Rabinowicz and Rønnow-Rasmussen, "A Distinction in Value," p. 39.

${ }^{31}$ Dancy, Ethics without Principles, p. 170.

${ }^{32}$ Moore cannot allow this sort of possibility because, as we saw earlier, he holds that intrinsic value depends solely upon the intrinsic value of the thing. This leaves no room for the possibility of something else being able to affect the intrinsic value of a thing. To put this in the terms just used, Moore's position identifies the supervenience base of intrinsic value with its ground. For interesting discussion of this, see Dancy, Ethics without Principles, p. 178.

${ }^{33}$ Ibid., pp. 41-42.

${ }^{34}$ This intensifying/attenuating role could be played by an intrinsic feature of the pleasure or by an extrinsic feature.
} 
presents what could have been Mill's view, thus:

But there is a point I wish to mention here. By calling a thing "intrinsically good" or "good-in-itself" I do not mean to commit myself to the view that it would necessarily be good in all contexts or could still be good if everything else in the universe were different. "Good-in-itself" has been used in this sense; but it need not imply this, as far as I can see. What I mean by "good-in-itself" is simply "good itself," in opposition to good as a means; that is, I mean that the thing called good really has the characteristic goodness in its primary sense, and is not merely called good because it produces something else which has the quality in question. ${ }^{35}$

\section{The Uniqueness of Moore's View}

Mill's discussion of the intrinsic value (or lack thereof) of the good will links to a more general point of this paper: that Moore was insufficiently attentive to how revisionary (or at least how specific) his understanding of value was. And Moore's unawareness that his position (however plausible it may be) was new partly distorted his understanding and treatment of other positions.

Another example of how Moore's projection of his own view of intrinsic value distorts his treatment of other views is in his handling of Kant's discussion of the value of virtue. ${ }^{36}$ At the beginning of the Groundwork of the Metaphysic of Morals, Kant declares that "[i]t is impossible to conceive anything at all in the world, or even out of it, which can be taken as good without qualification, except a goodwill' and that intelligence, wit, judgement, power, health, honor, and happiness can only be good when accompanied by a goodwill. ${ }^{37}$ Note that Kant explicitly says of good will: "Such a will need not on this account be the sole and complete good, but it must be the highest good and the condition of all the rest, even of all our demands for happiness." these claims of Kant's, we can see that on Moore's account of intrinsic value, the good will would be intrinsically valuable (because it adheres to the intrinsicality and necessity theses). Everything else would be extrinsically (and ipso facto instrumentally) valuable (because it violates the two theses). ${ }^{39}$

\footnotetext{
${ }^{35}$ A.C. Ewing, The Definition of Good (London: Routledge and Kegan Paul, 1947), p. 114.

${ }^{36}$ Moore discusses Kant's claims regarding the value of the good will in his (Moore's) discussion of the value of virtue. I make no stand on whether this is the correct way to think about the good will.

${ }^{37}$ Immanuel Kant, Groundwork of the Metaphysic of Morals [1783], trans. H.J. Paton (London: Routledge, 1997), p. 59.

${ }^{38}$ Ibid., p. 62.

${ }^{39}$ On the (I think plausible) assumption that these other goods could exist in the absence of goodwill.
} 
And when Moore comes to discuss Kant's view of the value of virtue we find a familiar line of thought. Moore writes:

It is not commonly observed that if a thing is really to be a reward, it must be something good in itself: it is absurd to talk of rewarding a person by giving him something, which is less valuable than what he already has or which has no value at all. Thus Kant's view that virtue renders us worthy of happiness is in flagrant contradiction with the view, which he implies and which is associated with his name, that a Good Will is the only thing having intrinsic value. ${ }^{40}$

And as for Kant's implication that it is the sole good, this is inconsistent with other of his own views. For he certainly regards it as better to perform the actions, to which he maintains that it prompts us - namely, "material" duties - than to omit them. But, if better at all, then, these actions must be better either in themselves or as a means. The former hypothesis would directly contradict the statement that this motive was sole good. ${ }^{41}$

I think that Moore's line of thought in finding Kant inconsistent is very similar to that in his objection to Mill. Under the influence of his own view, Moore takes Kant to hold that good will is intrinsically good and everything else (such as happiness) is instrumentally good because it violates the necessity thesis (in virtue of being "merely" conditionally valuable). By combining this with his claim about the value of rewards, Moore's construction of Kant's apparent contradiction is complete and he dismisses Kant's account triumphantly. But clearly Moore is rejecting a hideously "Mooreified" Kant. And Moore had no grounds for taking this to be the real Kant-just as in his discussion of Mill, Moore neglects to consider that his view of intrinsic value was, in virtue of being so strict (by identifying the final with the intrinsic, and the essential), a new account. $^{42}$

\section{Why Care About This?}

So why should we care about this? Well, the main point is not to try to save qualitative hedonism, though I do think that qualitative hedonism is often rejected prematurely and that it would be worth getting clear on exactly why we should reject it, in both quality-as-intrinsic and qualityas-extrinsic forms. ${ }^{43}$

\footnotetext{
${ }^{40}$ Moore, Principia, p. 223 (my italics).

${ }^{41}$ Ibid., pp. 228-29 (italics in original). On the first sentence of this passage, Moore has a footnote in which he writes that Kant "so far as I know, never expressly states this view."

${ }^{42}$ For more on this, see Hurka, "Moore in the Middle," p. 606.

${ }^{43}$ If hedonists could get the quality-as-extrinsic version of the view to work-by explaining why the quality is capable of affecting the goodness of a pleasure though not itself a good-maker - this might open up the possibility of new forms of hedonism and hedonistic answers to previous difficulties (such as allowing for the possibility of
} 
Similarly, it is not particularly my aim here to tackle the exegetical question of exactly what conception of intrinsic value Mill held. My more modest aim is simply to suggest that in Moore's discussion of (one version of) Mill, as in his discussion of Kant on the value of the good will, we can see Moore's general (and distorting) tendency to:

(a) identify final value with intrinsic value,

(b) supplement (a) with a very strict account of intrinsic value (i.e., necessary value), and

(c) reduce the category of extrinsic value to instrumental value.

I think this is important because Moore's tendency is one that, perhaps regrettably, has exerted strong influence over thinking about value ever since - though it is, nowadays, being resisted. ${ }^{44}$ As pointed out by James Ward Smith, Moore's view of the extrinsic influenced the characterizations of intrinsic and extrinsic value in Charles Stevenson's Ethics and Language and Clarence Lewis's An Analysis of Knowledge and Valuation. ${ }^{45}$ Stevenson, for instance, presents the two types of value as follows:

In the sense here in question "intrinsically good" is roughly synonymous with "good for its own sake, as an end, as distinct from good as a means to something else."

"I approve of $x$ extrinsically" has the meaning of "The consequences of $x$ meet for the most part with my approval, and so I approve of $x$ when I consider it with exclusive regard to its consequences. ${ }^{, 46}$

As pointed out by Korsgaard, the perennial contrasting of the intrinsically valuable with the instrumentally valuable (and the treatment of extrinsic and instrumental value as identical) is testament to the effect that Moore's conception of value has had. I think it accurate to say that nowadays Moore's view is taken to be orthodoxy. ${ }^{47}$

This is not to deny that there have been dissenters along the way. I

posthumous harm).

${ }^{44}$ Defenders of Moore's view include: (Ben) Bradley, Chisholm, Feldman, Lemos, and Zimmerman. Dissenters from it, in various forms, include: Dancy, Ewing, Kagan, Korsgaard, O'Neill, and Rabinowicz and Rønnow-Rasmussen.

${ }^{45}$ Charles Stevenson, Ethics and Language (New Haven: Yale University Press, 1944); Clarence Lewis, An Analysis of Knowledge and Valuation (La Salle, Ill.: Open Court, 1946).

${ }^{46}$ James Ward Smith, "Intrinsic and Extrinsic Good," Ethics 58 (1948): 195-208, pp. 195-96, quoting Stevenson, Ethics and Language, pp. 174 and 177. Smith (p. 196) reports Stevenson as saying that this is a "workably clear" definition of extrinsic.

${ }^{47}$ Anthony Hatzimoysis, in "Sentimental Value," Philosophical Quarterly 53 (2003): 373-79, calls Moore's and Korsgaard's views of final value "orthodox" and "liberal," respectively. The title of Kagan's "Rethinking Intrinsic Value" is also apt in this regard. 
have already mentioned Ewing's position in The Definition of Good, and in "Intrinsic and Extrinsic Good," Smith objected to Moore's identification of the extrinsic with the instrumental. ${ }^{48}$ His reason for objecting to Moore's move was the recognition that there is more to the category of extrinsic value than simply instrumental value. As Smith puts the point:

What reader has not at some time or other placed a high degree of value on some thoroughly useless article simply by reason of the fact that it was made, or perhaps merely given, by someone dearly loved. Where such situations have been recognised in treatises on value, they have generally been dismissed as mere "associational values"... The mere labelling of a value as "associational" would be question-begging. Perhaps, indeed, any case of extrinsic evaluation requires some associational process in the evaluating mind. This would have no tendency to justify the prevalent equation of

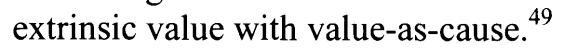

This issue of extrinsic final value brings out a further aspect of Moore's legacy that is significant and that we should reject: contemporary Mooreans' insistence that the only bearers of final value are states of affairs. ${ }^{50}$ Their reason for so insisting is to ensure that all final value is intrinsic value. To take an example discussed by Shelly Kagan, ${ }^{51}$ a nonMoorean might attribute final value to the pen used to sign the Emancipation Proclamation partly on account of its extrinsic properties, such as its age, historical significance, and uniqueness. When faced with such a candidate for partly-extrinsic final value, contemporary Mooreans insist that it is not the object itself that is finally valuable but rather the state of affairs "that the pen used to sign the Emancipation Proclamation exists," or something similar. ${ }^{52}$ And, as discussed above, what is an extrinsic property of the object - that it was used by Lincoln to sign the Emancipation Proclamation-is an intrinsic property of the state of affairs "that the pen used by Lincoln to sign the Emancipation Proclamation exists." And so, by insisting that it is only a state of affairs that can be the bearer of final value, the Moorean ensures that intrinsic value and final value remain one and the same.

Whether we think that this is a plausible response to what certainly seems like nonintrinsic final value is likely to depend on whether we are

\footnotetext{
${ }^{48}$ Smith, "Intrinsic and Extrinsic Good." In "Moore in the Middle" (p. 606), Hurka suggests that there are passages that might reflect a non-Moorean conception of intrinsic value in Sidgwick's discussions of the value of virtue and knowledge in The Methods of Ethics and in Rashdall's discussion of the effect of pleasure on the value of the virtue in The Theory of Good and Evil.

${ }^{49}$ Smith, "Intrinsic and Extrinsic Good," pp. 197-98.

${ }^{50}$ For discussion of these issues, see, e.g., Rabinowicz and Rønnow-Rasmussen, "A Distinction in Value." They label this Moorean tactic the "Reduction Manoeuvre" (p. 42).

${ }^{51}$ Kagan, "Rethinking Intrinsic Value," p. 104.

${ }^{52}$ For discussion of this case and Moorean responses to it, see, e.g., Ben Bradley, "Two Concepts of Intrinsic Value," Ethical Theory and Moral Practice 9 (2006): 111-30.
} 
already inclined towards Mooreanism about intrinsic and final value. Though I lack the space to argue for it here, I think that we would be forced to accept the claim that states of affairs are the sole bearers of final value if we were committed to Mooreanism about intrinsic and final value (namely, the identity of intrinsic and final value, their being held with necessity, and their being dependent solely upon the intrinsic properties of the bearers). However, in the absence of a prior motivation for these very strong claims, the move to states of affairs as being the sole bearers of final value seems not only unmotivated but also to be very much at odds with our ordinary understanding of what is finally valuable and, subsequently, the claims we make about the finally valuable.

One way in which it is so at odds is that in order to retain the claim that intrinsic and final value are borne with necessity, the Moorean must ensure that the value-bearing state of affairs is nothing less than a guarantee of final value. As such, the state of affairs that holds final value will not be "that X is happy." It will not be so because this state of affairs might not always be valuable, such as if it is the case that $\mathrm{X}$ is wicked. Thus to preserve the necessity of intrinsic value, Mooreans will have to incorporate X's not being wicked into the relevant state of affairs, so they must move to "that X is happy and not wicked." But, of course, things will not stop there, and certainly not for everything that is finally valuable. So the Moorean will have to build into the finally valuable state of affairs everything that can have an effect on what we would ordinarily say is the thing that is valuable - in this case, X's happiness. As such, the bearers of final value will be long conjunctive states of affairs, quite unlike anything that is cited as a bearer of final value in ordinary discussion of value.

A final reason for being interested in Moore's conception of intrinsic value, and its downplaying of the extrinsic ${ }^{53}$ is that it provides an interesting parallel with contemporary debate about practical reasons. Implicit in Moore's conception of intrinsic value is the idea that only a value bearer can make it the case that there is more (or less) value..$^{54}$ If a situation is better than another, this cannot be accounted for by something that is not, itself, a value bearer. And, similarly, nowadays many people hold that only a reason itself, or part of a fully specified "complete reason," can serve to explain why we have more reason to perform an action in one case than in another. For example, if my promise's having been freely given can affect the reasons I have to keep a promise to $\mathrm{X}$, this is because it is either an

\footnotetext{
${ }^{53}$ More specifically, its identification of the final with the intrinsic and reduction of the extrinsic to the instrumental.

${ }^{54}$ I say value bearer because, from Moore's doctrine of organic unities, a value bearer need not hold positive value outside of its inclusion in the organic unity to contribute positively towards the value present in the unity. That is to say, something that is otherwise bad can contribute to making a situation better (as in retributive punishment).
} 
additional reason or, more often, because it is a part of the completely specified reason, such as "I made a promise to $\mathrm{X}$ and this promise was freely given." Just as latterday Mooreans build into states of affairs anything that is necessary for determining intrinsic value-in a manner that thereby makes intrinsic (what would otherwise be) extrinsic properties - so too do some philosophers seek to build into a reason everything that is necessary for its so being a reason. ${ }^{55}$

\title{
8. Conclusion
}

It is not new to claim that qualitative hedonism can be consistent. ${ }^{56}$ What I think is new and interesting is to see just how unfair Moore was in his discussion and rejection of qualitative hedonism (for he could have made it consistent on his own terms in a number of ways). I also think it interesting to see how part of Moore's objection to qualitative hedonism (like his rejection of "Kant's" view of the good will) stemmed from his own substantive view of intrinsic value, one that was Moore's own and that Mill might not have held. ${ }^{57}$ But this is not simply an historical issue in the interpretation of Mill and Kant. The ideas underlying Moore's criticisms of their positions are very much alive in debates on value and reasons.

\author{
Guy Fletcher \\ Department of Philosophy \\ University of Reading \\ G.Fletcher@Reading.ac.uk
}

\footnotetext{
${ }^{55}$ Mark Schroeder discusses (and rejects) this view, which he calls "No Background Conditions," in his Slaves of the Passions (Oxford: Oxford University Press, 2007). The "No Background Conditions" view is defended by Roger Crisp, "Particularizing Particularism," in Brad Hooker and Margaret Little (eds.), Moral Particularism (Oxford: Oxford University Press, 2000); and B.W. Hooker, "Moral Particularism and the Real World," in Mark N. Lance, Matja $\square$ Potr $\square$, and Vojko Strahovnik (eds.), Challenging Moral Particularism (New York: Routledge, 2008). It is most prominently resisted by Dancy.

${ }^{56}$ See, for instance, Roger Crisp, Guidebook to Mill on Utilitarianism (London: Routledge, 1997), and John Skorupski, Why Read Mill Today? (London: Routledge, 2006). And further back, Frankena's objection to qualitative hedonism wasn't that it was inconsistent but rather that if one introduces a quality component in determining the value of a pleasure, "it is hard to see how the utilitarian standard is to be stated, and Mill never did make this clear." W.K. Frankena, Ethics, 2nd ed. (Englewood Cliffs, N.J.: Prentice Hall, 1973), p. 35.

${ }^{57}$ For helpful discussion and comments I would like to thank Jonathan Dancy, Brad Hooker, Debbie Roberts, Jussi Suikkanen, Chris Woodard, and two anonymous referees for Social Theory and Practice.
} 